\title{
Ectopic calcitonin secretion in a woman with large cell neuroendocrine lung carcinoma
}

\author{
Goran Cvijovic, ${ }^{1,4}$ Dragan Micic, ${ }^{1,4}$ Aleksandra Kendereski, ${ }^{1,4}$ Svetlana Zoric, ${ }^{1}$ \\ Mirjana Sumarac-Dumanovic, ${ }^{1,4}$ Svetislav Tatic, ${ }^{1,2,4}$ Aleksandar Trivic, ${ }^{1,3}$ \\ Danica Pejkovic-Stamenkovic, ${ }^{1}$ Danka Jeremic ${ }^{1}$
}

${ }^{1}$ Clinic for Endocrinology, Diabetes and Diseases of Metabolism, ${ }^{2}$ Institute of Pathology, ${ }^{3}$ Institute for Otorhynolaryngology and Maxillofacial Surgery, Clinical Center of Serbia, ${ }^{4}$ Faculty of Medicine, University of Belgrade, Serbia

\begin{abstract}
OBJECTIVE: Serum calcitonin (CT) is a sensitive but not specific marker for medullary thyroid carcinoma (MTC). There are a large number of conditions that may elevate CT levels. CASE REPORT: Herein we present the case of a 47-year old woman with Hashimoto thyroiditis, goiter, cervical lymphadenopathy and high CT and CEA levels. After surgical extirpation of the lymph node neuroendocrine cancer metastasis was suspected. Computed tomography of the chest showed a tumor mass on the right lung. Bronchoscopy was performed and pathological and immunohistochemical analysis revealed large cell neuroendocrine lung cancer (LCNEC). After chemotherapy, significant reduction of tumor mass was achieved with a moderate decrease in CT levels in parallel. CONCLUSIONS: We present a female with LCNEC, a condition which is usually observed in older men ( $7^{\text {th }}$ decade) and is not associated with CT secretion. Hashimoto thyroiditis is associated with increased incidence of different types of cancers (e.g. thyroid, colon). No reports at present exist on the incidence of lung cancers in patients with thyroid disease.
\end{abstract}

Key words: Calcitonin, Ectopic Secretion, LCNEC

\section{INTRODUCTION}

Serum calcitonin (CT) is considered as a sensitive marker of medullary thyroid carcinoma (MTC), and consecutive determination of CT in all patients with thyroid nodules as a screening procedure for the diagnosis of MTC has been proposed..$^{1,2}$ However, CT

Address for correspondence:

Goran Cvijovic, MD, MSc, Tel. +381-65-2292069;

Fax: +381-11-3065081, e-mail: cvijovicg@netscape.net

Received 10-02-2012, Accepted 07-10-2012 is not an especially specific marker for MTC: only 10$40 \%$ of all patients with thyroid nodules and elevated basal CT levels had MTC, ${ }^{3}$ with some patients being erroneously submitted to total thyroidectomy due to elevated CT levels. ${ }^{4}$ There are numerous conditions that might be associated with elevated basal CT levels such as hypergastrinemia (gastrinoma, atrophic gastritis, chronic use of omeprazole), ${ }^{5}$ hypercalcemia, ${ }^{6,7}$ renal insufficiency, ${ }^{8}$ thyroid carcinomas (follicular and papillary carcinomas), ${ }^{3,7}$ neuroendocrine tumors (paragangliomas, pheochromocytomas, insulinomas, 
VIPomas, neuroendocrine larynx, lung and pancreas carcinomas), ${ }^{9-12}$ other non-neuroendocrine carcinomas (breast, bronch, lungs) ${ }^{13-15}$ and drugs (beta blockers, glucagon, glucocorticoids). ${ }^{16}$

Controversial results have been reported regarding CT levels in Hashimoto thyroiditis. Thus, while elevated CT levels due to C-cell hyperplasia were reported in up to $12.5 \%$ patients with Hashimoto thyroiditis, ${ }^{17}$ other studies observed significantly lower basal and stimulated CT levels in patients with Hashimoto thyroiditis. ${ }^{18,19}$ Low CT levels are thought to be a consequence of inflammatory processes characterized by progressive lymphocytic infiltration that leads to follicular and parafollicular cell damage and C-cell destruction. ${ }^{20}$

Most of the abovementioned conditions are associated with CT levels between $10-100 \mathrm{pg} / \mathrm{ml}$. Constante et al suggested that basal CT levels higher than 100 $\mathrm{pg} / \mathrm{ml}$ are $100 \%$ predictive of MTC. ${ }^{21}$ In addition, basal CT levels much higher than $100 \mathrm{pg} / \mathrm{ml}$ (up to $9571 \mathrm{p} / \mathrm{ml}$ ) were reported in patients with ectopic CT secretion. ${ }^{12,14}$ Herein, we present a female with Hashimoto thyroiditis, goiter, cervical lymphadenopathy and very high basal CT levels secreted by large cell neuroendocrine lung cancer (LCNEC).

\section{CASE REPORT}

In a 47-year old female, Hashimoto thyroiditis with primary hypothyroidism (positive family history for Hashimoto thyroiditis) was diagnosed 20 months ago and therapy with L-thyroxine was initiated. After 6 months, ultrasound examination revealed multinodular goiter grade II-III and cervical lymphadenopathy (TSH was optimally suppressed on $150 \mathrm{mcg}$ of L-thyroxine therapy, CT was normal). Fine needle aspiration biopsy (FNAB) of the thyroid nodules confirmed the diagnosis of chronic thyroiditis. After one year she was referred to a gastroenterologist due to weight loss (20 kg/3 months) and pain in the epigastrium. The findings on ultrasound examination of the abdomen, gastroscopy and colonoscopy were normal. A paracardial tumor mass on the basal parts of the right lung was observed on X-ray examination (the patient is a smoker: 20-30 cigarettes per day). Multi-sliced computed tomography (MSCT) showed a $32 \mathrm{~mm}$ peripheral mass on the right lung with paratracheal and jugular lymphadenopathy. FNAB of an enlarged lymph node (LGL) located on the left side of the neck was performed in a Regional Health Center and the cytology finding was adenocarcinoma. Hormonal testing revealed high levels of calcitonin $(260 \mathrm{pg} / \mathrm{ml})$ and CEA $(31.7 \mathrm{ng} / \mathrm{ml})$, while TSH, PTH and calcium levels were normal as was also the total of the routine biochemistry analysis. The patient was referred to our Clinic as a patient with a MTC diagnosis.

On examination, the patient had a BMI of 22.5 $\mathrm{kg} / \mathrm{m} 2$ and was eumetabolic. She had multinodular goiter grade II, with a palpable firm and painless 20 $\mathrm{mm}$ lymph node located submandibular on the left side. The rest of the physical examination was unremarkable. Laboratory analysis revealed high basal CEA and CT levels without CT response during a calcium stimulation test (Tables 1 and 2). Procalcitonin levels were not determined. NSE and CYFRA 21 were slightly elevated. TSH (on $150 \mathrm{mcg}$ L-thyroxine therapy), chromogranin A (CGA), calcium, PTH, $\alpha$ - feto protein (AFP) and $\beta$-hcg were normal, as well as all of the routine biochemical analysis. Urine catecholamines were normal. RET mutation analysis was not performed.

Ultrasound examination of the neck revealed a

Table 1. Hormonal results

\begin{tabular}{lcc}
\hline Analysis & $\begin{array}{c}\text { Before } \\
\text { therapy }\end{array}$ & $\begin{array}{c}\text { After 6 cycles of } \\
\text { chemotherapy }\end{array}$ \\
\hline Calcitonin (ng/l, 0-10) & 303 & 152.3 \\
CEA (ng/ml, 0-4) & 31.7 & 10.1 \\
CYFRA 21-1 (mcg/l, 0-3.3) & 4.2 & 1.9 \\
Chromogranin A & 59.4 & \\
(ng/ml, 19.4- 98.1) & & \\
NSE (ng/ml, 4.7-14.7) & 23.4 \\
PTH (ng/l, 0-80) & 50.2 \\
Calcium (mmol/l) & 2.46 \\
AFP & 3.93 \\
B Hcg & 0.369 \\
\hline
\end{tabular}

Table 2. Calcitonin response during calcium stimulation test

\begin{tabular}{lcccc}
\hline $\mathbf{H}(\mathbf{m i n})$ & $\mathbf{0}$ & $\mathbf{1}$ & $\mathbf{2}$ & $\mathbf{5}$ \\
\hline Calcitonin $(\mathrm{pg} / \mathrm{ml})$ & 223.4 & 182.3 & 217.1 & 185.3 \\
\hline
\end{tabular}


significantly enlarged thyroid (grade III), hypoechogenic, lobulated, with significant fibrosis and without separated nodules. There was an enlarged lymph node on the left side (under bifurcation of CCA) of the neck, suspicious for metastasis. DMSA scintigraphy of the whole body and mammography were normal. The enlarged lymph node was surgically excised and the histological report suggested metastasis of a neuroendocrine carcinoma (Figure 1A).

MSCT of the chest revealed an infiltrative tumor formation in the lower part of the right lung connected with a package of LGL consisting of paratracheal, hilar, subcarineal LGLs (Figure 2A). No other metastases were observed. Bronchoscopy examination

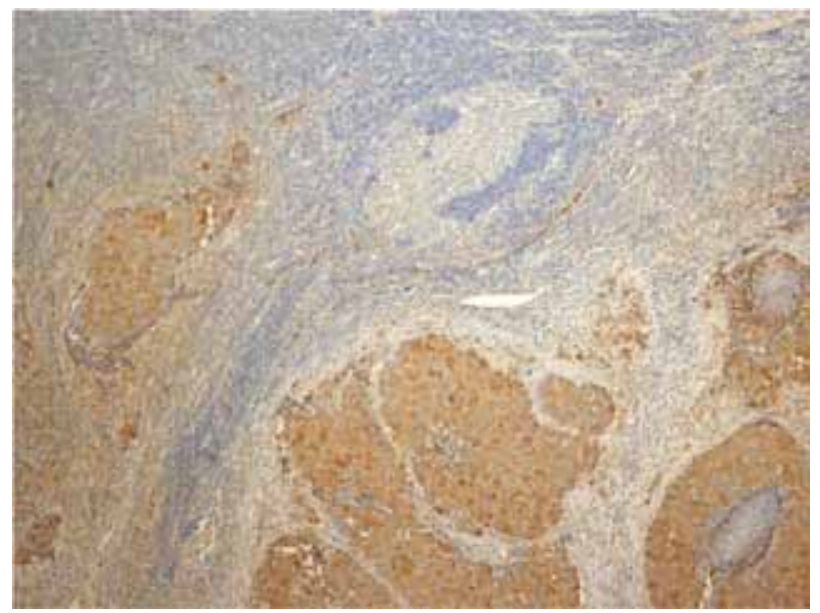

Figure 1A.

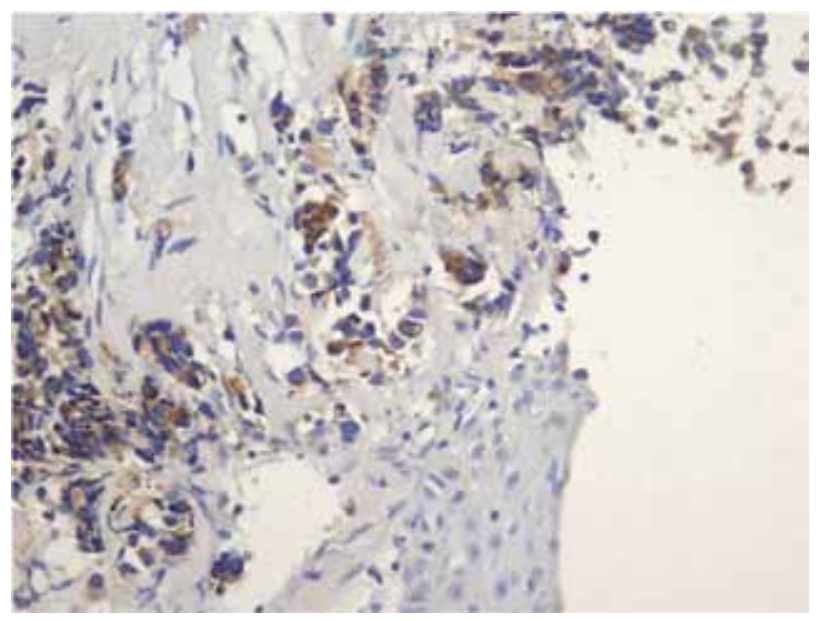

Figure 1B. revealed infiltration of both principal bronchi by malignant tissue. Biopsy was performed and cytological and imunohistological analysis findings revealed a large cell neuroendocrine cancer of the lung (LCNEC) positive for TTF, CGA, CT, CEA and negative for cytokeratin 20 (the finding was the same as it had been for the extirpated LGL from the neck) (Figure 1B). Ki 67 staining was $30 \%$.

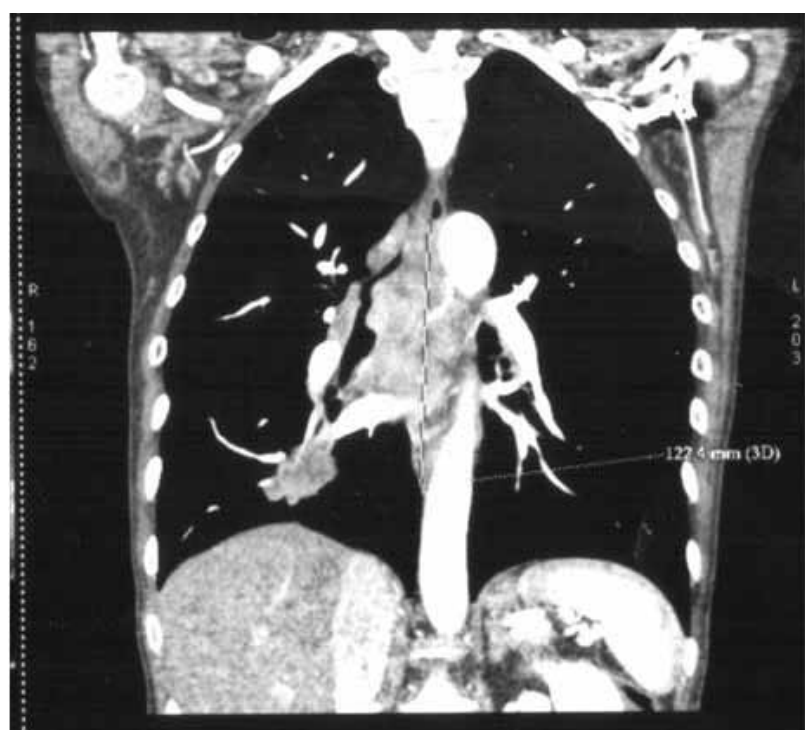

Figure 2A.

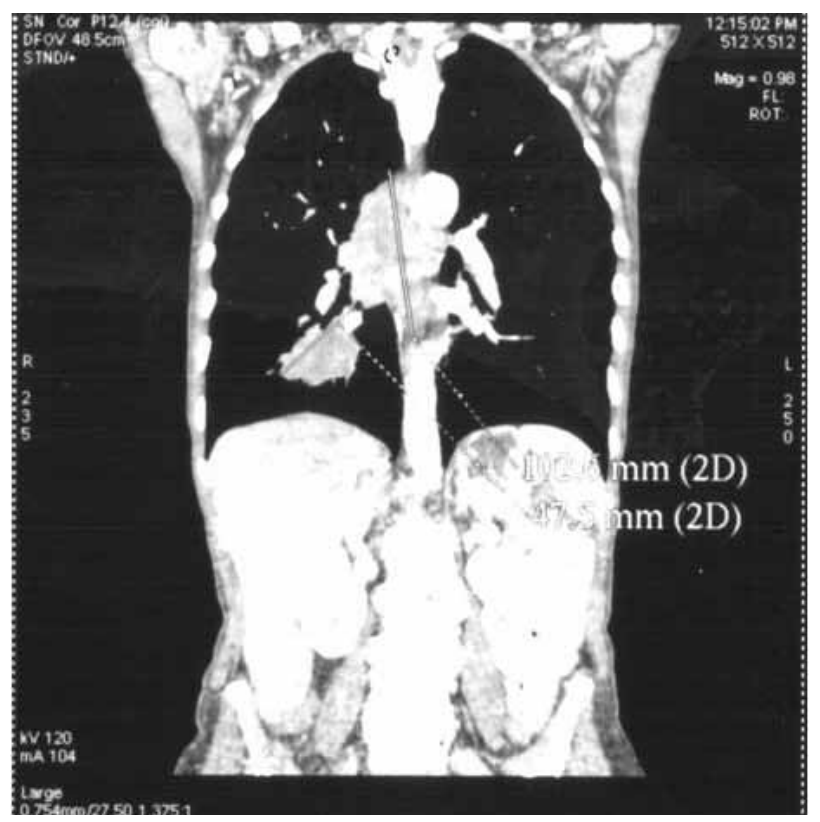

Figure 2B. 
Cisplatin-Etoposide combination therapy was started and after 6 therapeutic cycles control MSCT visualization observed reduction of the tumor and the LGL mass by approximately $30 \%$ (Figure 2B), while $\mathrm{CT}$ and CEA levels were moderately decreased (Table 1). Since the octreoscan $\left({ }^{111}\right.$ In-pentetreotid $)$ examination was positive in projection of tumor, the patient was sent for PRRT (Peptide Receptor Radionuclide Therapy) (Figure 3). After one course of PRRT the patient developed pneumonia and died.

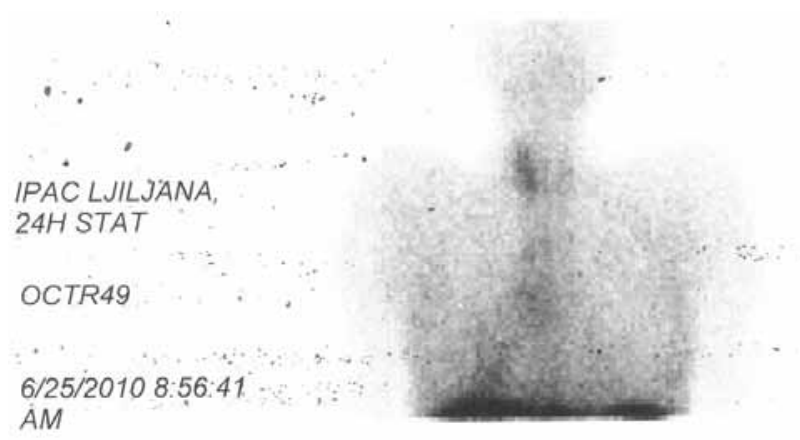

Whole body

Figure 3.

\section{DISCUSSION}

We present a female patient with large multinodular goiter, neck lymphadenopathy and high CT and CEA levels suggesting the diagnosis of MTC. Careful and detailed evaluation of the patient led us to the diagnosis of ectopic CT secretion originating from LCNEC.

High basal CT levels in this case together with goiter and cervical lymphadenopathy suggested MTC. Some authors have proposed that basal CT levels above $100 \mathrm{pg} / \mathrm{ml}$ are $100 \%$ predictive for $\mathrm{MTC}^{7}{ }^{7}$ but there have been several reported cases with basal CT levels much higher than $100 \mathrm{pg} / \mathrm{ml}$ in patients with ectopic secretion of CT, ${ }^{12,14,22}$ as was our case. Moreover, in our case, during a calcium stimulation test there was no CT response, as was observed during other stimulation tests in patients with ectopic CT secretion. ${ }^{10}$ High CT levels might be associated with secretory diarrhea and hypokalemia, as has been observed in patients with pancreatic and pulmonary tumors, ${ }^{23,24}$ but in most of these cases with ectopic CT secretion and paraneoplastic syndrome, elevated CT levels were associated with ectopic secretion of other hormones (Vasoactive Intestinal peptide - VIP, insulin, somatostatin, ...). ${ }^{12,25,26}$ Our patient did not have diarrhea or any other paraneoplastic symptom/sign nor any ectopic secretion of other hormones (except tumor markers: NSE, CEA and CYFRA 21-1). Furthermore, CT levels in our patient's serum were not extremely high, which might be one of the reasons why she did not have diarrhea.

There are several reports of ectopic CT secretion in patients with pulmonary tumors. Most frequently these concern patients with small cell lung carcinoma (SCLC) and pulmonary carcinoids..$^{10,24,27}$ In approximately $20 \%$ of patients with non-small cell lung carcinoma (NSCLC) - adenocarcinoma, squamous cell carcinoma and large cell carcinoma, cancer may display neuroendocrine differentiation and clinically present with paraneoplastic endocrine syndromes. Pratz et al reported a 38-year old male patient with large cell lung carcinoma with neuroendocrine differentiation and ectopic secretion of CT and VIP. He had extremely high basal levels of CT (approximately 10,000 pg/ml) and CEA (161 ng/ $\mathrm{ml}$ ), much higher than those in our case. However, in the above case there was also ectopic secretion of VIP and consecutive diarrhea. Cisplatin-Etoposide chemotherapy induced transient $\mathrm{CT}$ reduction and clinical improvement, as was achieved in our case. ${ }^{12}$ Monsieur I et al presented the case of a 58-year old man, a smoker, with NSCLC (poorly differentiated adenocarcinoma) with neuroendocrine differentiation and multiple paraneoplastic syndromes. In this patient, ectopic Cushing syndrome, elevated CT levels, SIADH, tylosis, hypertrophic pulmonary osteoarthropathy and erythema anulare were observed. ${ }^{14}$ Interestingly, this patient had a euthyroid diffuse goiter, but, since the antiTPO antibody was not determined, we do not know if the patient had Hashimoto thyroiditis.

Epidemiological data suggest that LCNEC is a rare tumor and that it occurs significantly more commonly in men (80-90\%), most frequently in the $7^{\text {th }}$ decade and almost always in patients with a history of smoking (95-100\% of patients) ${ }^{28,29}$ In our case the patient was a 47-year old women, which is unusual for 
this type of lung cancer, but she was a smoker. The location and size of the tumor at presentation were typical for LCNEC, a type of tumor that is characterized by poor prognosis. This high-grade cancer has 5 -year survival rates of $13-47 \%$, i.e. almost the same as SCLC. ${ }^{29}$ Elevated CEA levels can be detected in $50 \%$ of patients with LCNEC, while NSE was observed in $12.4 \%$ of these patients. ${ }^{29}$ Elevated NSE and CYFRA 21-1 levels are associated with poor outcome. ${ }^{30}$

The treatment options for neuroendocrine tumors are surgical resection of tumor mass and/or therapy with cytotoxic drugs, inhibitors of angiogenesis, somatostatin analogs and receptor targeted radiotherapy. ${ }^{31}$ Surgical therapy is the treatment of choice when it is applicable. ${ }^{32}$ Adjuvant pre- and postoperative chemotherapy was associated with better outcome in patients with stage I LCNEC. ${ }^{33}$ Moreover, Rossi et al demonstrated that adjuvant platinum-etoposide based chemotherapy can be very effective and significantly improves survival in stage I, II and III LCNEC patients..$^{34}$ On the other hand, chemotherapy is usually associated with significant side effects and the median time to progression is mostly shorter than 18 months..$^{35}$

Therapy with long-acting somatostatin analog (octreotide LAR) provides relief of symptoms and stabilization of tumor growth in patients with functionally active and inactive midgut neuroendocrine tumors. ${ }^{31,36}$ In patients with LCNEC, adjuvant therapy with octreotide alone or with radiotherapy demonstrated significant efficacy when preoperative indium In-111 pentetreotide scintigraphy was positive. ${ }^{37}$ Radiolabeled somatostatin analogs therapy, named peptide receptor radionuclide therapy (PRRT), was associated with significant tumor response rate and progression-free survival and was very safe compared to other treatment modalities in patients with foregut and midgut neuroendocrine cancers. Treatment with ${ }^{177} \mathrm{Lu}$-octreotate resulted in tumor reduction in $46 \%$ of patients, stable disease was observed in $35 \%$ of patients and the median time to progression was 40 months. ${ }^{38}$ The better the tumor uptake on somatostatin receptor scintigraphy with ${ }^{111}$ In-DTPA ${ }^{0}$ octreotide, the better the results that can be expected using PRRT. Furthermore, an additional treatment cycle can be safely administered when disease becomes active again. The results of additional therapy are less effective than with initial treatment. ${ }^{39}$ Our patient exhibited an excellent response to chemotherapy with cisplatin-etoposide. However, the effect of PRRT therapy could not be observed since the patient died due to pneumonia soon after the first cycle was administered. Therapy with tyrosine kinase inhibitors (TKI) such as vandetanib is not available in our country.

Increased incidence of thyroid, breast, gastric and colorectal cancer was observed in patients with Hashimoto thyroiditis. ${ }^{40-44}$ Larson et al demonstrated that P-Akt, Akt 1 and Akt 2 components of the PI3K pathway were highly expressed in Hashimoto thyroiditis (HT), HT-associated thyroid cancer and thyroid cancer alone. Previously, increased PI3K activity was observed in colon, thyroid and ovarian cancers. We did not find any report suggesting an association between chronic thyroiditis and/or thyroid function and lung carcinoma, nor increased PI3K activity in lung carcinoma.

In conclusion, we herein report a female patient who clinically presented with goiter, cervical lymphadenopathy and elevated CT levels. Careful examination demonstrated that the patient had LCNEC with ectopic CT secretion. Interesting points of this case are the following: a) that it concerned a young woman with LCNEC (this type of tumor is usually diagnosed in 60-70 year old men), b) that ectopic CT secretion is usually seen in patients with other types of lung cancer (SCLC and carcinoids), c) that it raises the question as to whether there is a possible association between thyroid disease and lung cancer.

\section{REFERENCES:}

1. Hahm JR, LeeMS, Min YK, et al, 2001 Routine measurement of serum calcitonin is useful for early detection of medullary thyroid carcinoma in patients with nodular thyroid disease. Thyroid 11: 73-80.

2. Vierhapper H, Raber W, Bieglmayer C, et al, 1997 Routine measurement of plasma calcitonin in nodular thyroid disease. J Clin Endocrinol Metab 82: 1589-1593.

3. Borget I, De Pouvourville G, Schlumberger M, 2007 Calcitonin determination in patients with nodular thyroid disease. J Clin Endocrinol Metab 92: 425-427.

4. Marsh DJ, McDowall D, Hyland VJ et al, 1996 The identification of false positive responses to the pentagastrin stimulation test in RET mutation negative members of MEN 2A families. Clin Endocrinol (Oxf.) 44: 213-220.

5. Freston JW, 1994 Omeprazole, hypergastrinemia, and 
gastric carcinoid tumors. Ann Intern Med 121: 232-233.

6. Conte-Devolx B, Morlet-Baria N, Roux FSebag F, Henry JF, Niccoli P, 2010 Could primary hyperparathyroidism - related hypercalcemia induce hypercalcitoninemia? Horm Res Paediatr 73: 372-375.

7. Toledo S, Lourenco Jr DM, Santos MA, et al, 2009 Hypercalcitoninemia is not patognomonic of medullary thyroid carcinoma. Clinics 64: 699-706.

8. Niccoli P, Brunet P, Roubicek C, et al, 1995 Abnormal calcitonin basal levels and pentagastrin response in patients with chronic renal failure on maintenance hemodialysis. Europ J Endocrinol 132: 75-81.

9. Pinto FR, Capelli FA, Maeda SA, Unusual location of cervical paraganglioma between the thyroid and the common carotid artery: case report. Clinics 63: 845-848.

10. Machens A, Haedecke J, Holzhausen H-J, et al, 2000 Differential diagnosis of calcitonin-secreting neuroendocrine carcinoma of the foregut by pentagastrin stimulation. Langenbeck's Arch Surg 385: 398-401.

11. Leboulleux S, Baudin E, Young J, et al, 1999 Gastroenteropancreatic neuroendocrine tumor metastasis to the thyroid gland: differential diagnosis with medullary thyroid carcinoma. Eur J Endocrinol 140: 187-191.

12. Pratz KW, Ma C, Aubry M-C, Vrtiska TJ, Erlichman C, 2005 Large cell carcinoma with calcitonin and vasoactive intestinal polypeptide-associated Verner-Morrison Syndrome. Mayo Clin Proc 80: 116-120.

13. Coombes RC, Easty GC, Detre SI, et al, 1975 Secretion of immunoreactive calcitonin by human breast carcinomas. BMJ 4: 197-199.

14. Monsieur I, Meysman M, Noppen M, et al, 1995 Nonsmall-cell lung cancer with multiple paraneoplastic syndromes. Eur Respir J 8: 1231-1234.

15. Scheider R, Heverhagen AE, Moll R, Bartsch DK, Shlosser K, 2010 Differentiation between thyroidal and ectopic calcitonin secretion in patients with coincidental thyroid nodules and pancreatic tumors - a report of two cases. Exp Clin Endocrinol Diabetes 118: 520-523.

16. Gagel RF, Marx SJ, 2003 Multiple Endocrine Neoplasia. In: Williams Textbook of Endocrinology. Larsen PR, Kronenberg HM, Melmed S, Polonsky KS (eds) $10^{\text {th }}$ ed. Philadelphia: Saunders; pp, 1717-1762.

17. Barbot N, Guyetant S, Beldent V, et al, 1991 Chronic autoimmune thyroiditis and C-cell hyperplasia. Study of calcitonin secretion in 24 patients. Ann Endocrinol (Paris), 52: 109-112.

18. Borges MF, Abelin NM, Menezes FO, Dahia PL, Toledo SPA, 1998 Calcitonin deficiency in early stages of chronic autoimmune thyroiditis. Clin Endocrinol (Oxf.) 49: 69-75.

19. Poppe K, Verbruggen LA, Velkeniers B, Finne E, Body JJ, Vanhaelts L, 1999 Calcitonin reserve in different stages of chronic autoimmune thyroiditis. Thyroid 9: 1211-1214.

20. Lima SA, Santos BM, Borges MF, 1998 Quantitative analysis of C cells in Hashimoto's thyroiditis. Thyroid 8: 505-509.
21. Constante G, Meringolo D, Durante C, et al, 2007 Predictive value of serum calcitonin levels for preoperative diagnosis of medullary thyroid carcinoma in a cohort of 5817 consecutive patients with thyroid nodules. J Clin Endocrinol Metab 92: 450-455.

22. Ichimura T, Kondo S, Okushiba S, Morikawa T, Katoh H, 2003 A calcitonine and vasoactive intestinal peptideproducing pancreatic endocrine tumor associated with WDHA syndrome. Int J Gastrointest Cancer 33: 99-102.

23. Fleury A, Flejou JF, Sauvanet A, et al, 1998 Calcitonine-secreting tumors of the pancreas: about six-cases. Pancreas 16: 545-550.

24. Amann ST, Myers MA, Cicale MJ, 1994 Severe diarrhea and Cushing's syndrome from an atypical bronchial carcinoid. South Med J 87: 855-857.

25. Do Cao C, Mekinian A, Ladsous M, et al, 2010 Hypercalcitonemia revealing a somatostatinoma. Ann Endocrinol 71: 553-557.

26. Pusztai P, Sarman B, Illyes G, et al, 2006 Hypercalcitoninemia in a patient with a recurrent goiter and insulinoma: a case report. Exp Clin Endocrinol Diabetes 114: 217-221.

27. Kelley MJ, Becker KL, Rushin JM, et al, 1994 Calcitonin elevation in small cell lung cancer without ectopic production. Am J Respir Crit Care Med 149: 183-190.

28. Gustafsson B, Kidd M, Chan A, Malfertheiner M, Modlin I, 2008 Bronchopulmonary neuroendocrine tumors. Cancer 113: 5-21.

29. Asamura H, Kameya T, Matsuno Y, et al, 2006 Neuroendocrine neoplasms of the lung: a prognostic spectrum. J Clin Oncol 24: 70-76.

30. Hatzakis KD, Froudarakis ME, Bouros D, Tzanakis N, Karkavitsas N, Siafakas NM, 2002 Prognostic value of serum tumor markers in patients with lung cancer. Respiration 69: 25-29.

31. Rinke A, Muller H-H, Schade-Brittinger C, et al, 2009 Placebo-controlled, double-blind, prospective, randomized study on the effect of octreotide LAR in the control of tumor growth in patients with metastatic neuroendocrine midgut tumors: a report from the PROMID study group. J Clin Oncol 27: 4656-4663.

32. Srirajaskanthan R, Toumpanakis C, Karpathakis A, et al, 2009 Surgical management and palliative treatment in bronchial neuroendocrine tumours: a clinical study of 45 patients. Lung Cancer 65: 68-73.

33. Veronesi G, Morandi U, Alloisio M, et al, 2006 Large cell neuroendocrine carcinoma of the lung: a retrospective analysis of 144 surgical cases. Lung Cancer 53: 111-115.

34. Rossi G, Cavazza A, Marchioni A, et al, 2005 Role of chemotherapy and the receptor tyrosine kinases KIT, PDGFR $\alpha$, PDGFR $\beta$, and Met in large-cell neuroendocrine carcinoma of the lung. J Clin Oncol 23: 8774-8785.

35. O`Toole D, Hentic O, Corcos O, Ruszniewski P, 2004 Chemotherapy for gastroenteropancreatic neuroendocrine tumors. Neuroendocrinology 80: 79-84.

36. Oberg K, Kvols L, Caplin M et al,Consensus report on the use of somatostatine analogs for the management 
of neuroendocrine tumors of the gastroenteropancreatic system. Ann Oncol, 2004; 15: 966-973.

37. Filosso PL, Ruffini E, Oliaro A, et al, 2005 Large-cell neurondocrine carcinoma of the lung: a clinicopathologic study of eighteen cases and the efficacy of adjuvant treatment with octreotide. J Thorac Cardiovasc Surg 129: 819-824.

38. Kwekkeboom DJ, de Herder WW, Kam BL, et al, 2008 Treatment with the radiolabeled somatostatin analog $\left({ }^{177} \mathrm{Lu}-\mathrm{DOTA}{ }^{0}, \mathrm{Tyr}^{3}\right)$ Octreotate: toxicity, efficacy, and survival. J Clin Oncol 26: 2124-2130.

39. Van Essen M, Krenning EP, Kam B, de Herder W, Feelders R, Kwekkeboom D, 2010 Salvage therapy with Lu-octreotate in patients with bronchial and gastroenteropancreatic neuroendocrine tumors. J Nucl Med 51: 383-390.
40. Larson S, Jackson L, Riall T, et al, 2007 Increased incidence of well-differentiated thyroid cancer associated with Hahimoto's thyroiditis and the role of PI3K/AKT pathway. J Am Coll Surg 204: 764-775.

41. Itoh K, Maruchi N, 1975 Breast cancer in patients with Hashimoto's thyroiditis. Lancet 2: 1119-1121.

42. Syrigos K, Konstantoulakis M, Constantoulakis M, Marafelia P, Koutras D, Golematis B, 1994 Thyroid autoantibodies and thyroid function in patients with gastric cancer. Acta Oncologica 33: 905-907.

43. Rose DP, Davis TE, 1981 Plasma thyronine levels in carcinoma of the breast and colon. Arch Intern Med 141: 1161-1164.

44. Bech K, Bliddal H, Feldt-Rassmussen U, et al, 1984 Heterogenecity of autoimmune thyroiditis. Allergy 39: 239-247. 